\title{
UNIDADE DE ATO NO TESTAMENTO CONJUNTIVO
}

\author{
Armando Dias de Azevedo \\ Professor Catedrático de Direito Civil \\ as Faculdades de Direito das Universidade
do Rio Grande do Sul e Católica
}

E' o testamento conjuntivo ou de mão comum espécie perenta no direito pátrio, em que, aliás, penetrou através de praxe, sem amparo legal.

Autorizaram-no os praxistas (1), tirando argumento das Ordenações Filipinas, nos dispositivos em que determinam sejam marido e mulher considerados como "um corpo" ou como "uma pessoa":

“...marido e mulher... que são havidos por hum (sic) corpo" $\left({ }^{2}\right)$;

“...marido e molher (sic)... que não pagarão (sic) senão como huma ( $\mathrm{sic}$ ) pessoa" $\left({ }^{3}\right)$.

TEIXEIRA DE FREITAS consagrou o testamento conjuntivo em nota da terceira edição da Consolidação das Leis Civis ${ }^{4}$ ), e CARLOS DE CARVALHO, na art. 1754 da Nova Consolidação, in verbis:

"É permitido aos cônjuges, salvo o caso do art. 1458 $\left.{ }^{5}\right)$, fazer testamento de mão comum, podendo qualquer dêles revogá-lo na constância do casamento ou depois de sua dissolução; entende-se, porém, revogado quando o casamento é declarado nulo ou anulado e pela superveniência do divórcio.

(1) VALASCO, Consult., VII; LOBÃO, Notas a MELO, Supl., Dissert. 7, \& 27;

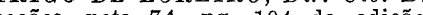
edicão acomodada ao fôro do Brasil por TEIXEIRA DE FREITAS: FERREIRA ALVES, Consollaçăa das deis uo juizo da provedoria, vol. I, \& 144 e nota, pgs, 160-170.

(2) Ord. L. L (3. $^{\circ} . \circ$, tit. $31, \$ 1.0^{\circ}$

(4) Nota 1 ao art. 105

(5) "A mulher, que se casar com infração do $\S 8$ do art. 1399, não poderá fazer testamento, nem comunicar com 0 matido art. 1458).

"D. 181 cit. art. 100" (CARLOS DE CARVALHO, Nova Consolidaşão,

5 - R. D. $1 .^{\circ}$ Vol. 
"Arg. ex Ord. 1, 31, 1. - Ord. 1, 62, 46. - Ord. 1, 84, 3. - D. 3363 de 1899 , tab. III, n. ${ }^{\circ} 51$ c) - Ex. Ord. $4,84,2,4$ in f. - D. 181 de 1890 , arts. $75,78,88,92$ e 100. - T. de Fr. C. art. 1053 (nota)".

A inconveniência do tèstamento de mão comum, espécie anômala $\left(^{6}\right)$, foi apontada por tratadistas $\left({ }^{7}\right)$, devido ao perigo de pacto sucessório $\left({ }^{8}\right)$ e pela dificuldade de revogação - ambulatoria est voluntas defuncti usque ad vitae supremum exitum $\left({ }^{9}\right)$, - maugrado os textos da Ord. L. ${ }^{0} 4$, tit. $84, \S 2\left({ }^{10}\right)$ e $\S 4$, in fine ( $\left.{ }^{11}\right)$.

Bem fêz, pois, o legislador pátrio fulminando o testamento de mão comum com proibição insofismável, pelo art. 1630 do Código Brasileiro:

"É proibido o testamento conjuntivo, seja simultâneo, recíproco ou correspectivo".

Ficou, assim, abolida essa aberração que brigava com a característica do testamento - ato personalíssimo, unilateral, gratuito, solene e revogável $\left({ }^{12}\right)$.

Aceitam - é certo - o testamento conjuntivo para marido e mulher o direito inglês (13) e os Códigos Civis da Alemanha (art. 2265), da Áustria (arts. 583, 601, 1217 e 1248) e da Venezuela (art. 824). Apenas para cônjuges, aliás, como acima ficou dito, aceitavam-no também os nossos praxistas.

Quanto ao Código Civil Alemão, tão adiantado em certas matérias, quão retrógrado em outras, o art. 2265 estatui que "um testamento comum não pode ser feito senão por esposos" e chega a ad-

(6) CANDIDO MENDES, Oódigo Filipino, nota 1 ao tit. 80, vb. Tab. publ.

(8) FRANCISCO MORATO, Miscelânea jurídica, vol. II, 1899.

(9) Dig. 34,4,fr. 4, in fine.

herdeiros instituídos tho impedirem, o que ja $\tilde{a}_{\text {tenh }}$ feu testamento, o quizer revogar, e os quanto o testador teve vontade declarada de o revogar, se se the nấo impedira. herança se applicará a nossa Coroa, como deixada a pessoas indignas"".
(11) "... Porém, se - a mulher tivesse feito testamento, em que năo deirasse cousa alguma a seu marido, ou o marido, em que outro si não deixasse cousa año alguma a a mulhex por offensas, ou discordias, que entre elles houvesse, e cada hum delles com palavras brandas aplacasse o animo do outro, de maneira que viesse a fazer outro segundo
testamento, em que o marido deixasse a sua mulher a fazenda, ou parte della, ou a (12) BEVILĀQUA, Sucessões,

(13) "Art. 198. - Testaments conjoints. 189 da ed. de 1899.
Si deux ou plusieurs personnes font conjointement un testament ou un codicille, où séparément des testaments ou codicilles en termes identiques, $l^{\prime}$ une de ces personnes peut en tout temps révoquer ou modifier la partie du testament ou codicille collectif qui la concerne, ou son testament ou codicille
séparé. Mais si l' une des parties décèd et si l' autre ou les autres bénéficient de dispositions de son testament, ils seront tenus sur leur patrimoine, en cas de modification de leurs testaments, d' exécuter l' accord primitif. Si ' une des parties an testament ou au codicille décede, le probate sera accordé pour la partie de l' acte qui produit se
effets à sa mort" (EDOVARD JENKS et autres, Digeste de Droit Oivil pgs. 176-177). mitir, nos arts. 2274 a 2302, o "contrato de herança", que nada mais é do que o geralmente reprovado "pacto sucessório", repelido pelo art. 1089 do Código Civil Brasileiro, como já o era pela Ord. L. ${ }^{\circ} 4$, tit. $70, \S 3 .^{\circ}\left({ }^{14}\right)$.

O Código BUSTAMANTE, magnífica convenção dos países americanos para o direito internacional privado, no art. 148, considera de ordem pública internacional as disposições que não admitem o testamento de mão comum, o ológrafo e o nuncupativo, bem como as que declaram o testamento ato personalíssimo.

O Código Civil Brasileiro proibiu, pois, as três formas de testamento conjuntivo, que eram enumeradas pelos autores - simultâneo, recíproco e correspectivo.

Tínhamos o simultâneo quando o casal testava em conjunto em favor de terceiros.

No recíproco, os cônjuges dispunham juntos, instituindo um ao outro herdeiro do sobrevivente.

Correspectivo era o testamento em que, juntos, dispunham marido e mulher um a favor do outro ou de terceiro, em retribuição dêsse outro.

Sempre se entendeu que era da essência do testamento conjuntivo sua feitura no mesmo ato - unitas acti.

Portanto, a proibição do art. 1630 do Código Civil Brasileiro só se pode referir a testamento em que os cônjuges, no mesmo ato, disponham de suas vontades.

\section{E' a lição de FERREIRA ALVES:}

“A proibição da lei compreende ùnicamente o testamento feito por duas ou mais pessoas no mesmo ato, não impede que duas ou mais pessoas convenham, cada uma por sua parte, dispor de seus bens, a favor de um terceiro, ou em favor de um e de outro, ficando cada um legalmente com o direito de revogar seu testamento, quando parecer conveniente" $\left({ }^{15}\right)$.

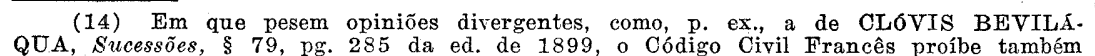
QUA, pactos sucessórios (arts. 791, 1130,1389 e 1600 ), mesmo em contratos antenupciass.
Eis a ementa dum acórdão da Câmara Cível da Côrte de Cassąâao de França, de 11 de janeiro de 1933

d' une succession notion ayant pour objet d' attribuer un droit privatif sur tout ou partie loi, encore que celui de la succession duquel il s s' agit y yat consenti,
"Cett prohibition est formelle et d' ordre public et ne comporte $d$ ' autres dérogations que celles qui sont limitativement déterminées par la loi. "Spécialement, la clause d" un contrat de mariage établissant le régime de la séparation de biens qui permet au conjoint survivant de prendre dans la succesion du prémourant
le fonds de comimerce ou les droits sociaux appartenant $\grave{a}$ celui-ci, $\grave{a}$ charge $d^{\prime}$ en payer le fonds de commerce ou les droits sociaux appartenant à celui-ci, à charge d' en paye

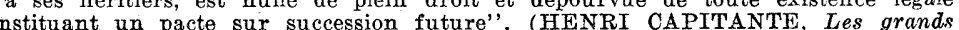
comme constituant un pacte sur succession future".
arrêts de la Jurisprudence Civile, n. ${ }^{\circ}$ 184, pg. 530. 
Em idênticas considerações abunda CÂNDIDO DE OLIVEIRA FILHO:

“As deixas feitas simultâneamente com cláusulas de reciprocidade ou correspectividade não incorrem em proibição desde que os testadores as façam em cédulas diversas.

"O que o art. 1630 do Código Civil proíbe é ùnicamente a disposição conjuntiva nesse aspecto especial uno contexto" $\left({ }^{16}\right)$.

CARVALHO SANTOS comenta o dispositivo do art. 1630 do nosso Código Civil no mesmo sentido:

"De acôrdo com a melhor doutrina, nada obsta a que diversas pessoas, em atos separados, disponham em favor de um terceiro, ou, mesmo, em proveito recíproco.

"Pouco importa mesmo que tais disposições tenham sido feitas ao mesmo tempo, a dizer - na mesma data, e nos mesmos têrmos, desde que estejam consagradas em atos distintos e independentes (Cfr. AUBRY ET RAU, obr. cit. §667 e nota 3; LAURENT, obr. cit. vol. 13, n. $\left.{ }^{\circ} 146\right) "\left({ }^{17}\right)$.

ITABAIANA ensina:

"O Código Civil, no art. 1630, proibiu o testamento conjuntivo ou de mão comum, seja simultâneo, recíproco ou correspectivo; sem obstar, entretanto, que, em atos separados, os cônjuges façam liberalidades recíprocas ou mútuas ou em favor de terceiros" $\left.{ }^{18}\right)$.

Não menos clara, mas, ao contrário, dando a razão de ser da norma proibitiva, é a lição de CARLOS MAXIMILIANO:

"Tal proibição não impede que duas pessoas combinem o modo de dispor dos seus bens, desde que o façam em atos separados; é lícito estabelecerem tanto a reciprocidade do benefício como a simultâneidade, isto é, uma deixar a fortuna para a outra, ou as duas para um

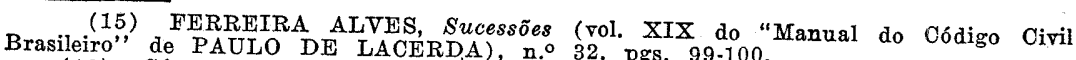
Brasileiro" de PAULO DE LACERDA), n. 32, pgs. 99.100.
(16) CANDIDO DE OLIVEIRA FILHO, Pratica Oivit, vol. XI (Direito das

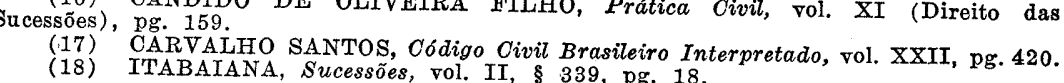

terceiro. Em tal hipótese, há de conservar cada testador a sua plena liberdade de ação; quando um só revoga a sua liberalidade, a do outro prevalece" $\left.{ }^{19}\right)$.

Discrepa dessa exegese do texto legal PONTES DE MIRANDA que, ao invés de interpretar a norma do art. 1630 de modo estrito, como disposição de caráter excepcional, proibitiva, que é, pretende que a proibição abranja não só o conjunto espacial e temporal, mas até o intencional, o que, no seu entender, anularia testamentos em que os cônjuges tivessem combinado suas disposições de última vontade, deixando para as mesmas pessoas em testamentos separados, feitos no mesmo dia, em têrmos similares, deslembrado de que, em tema de nulidades, não é lícito ir além das enumeradas na lei.

"Onde há reciprocidade e correspectividade, - afirma PONTES DE MIRANDA - há intenção de testar em conjunto. Não é preciso que se dê simultâneamente a identidade ou continuidade especial. Dois testamentos podem ser em atos diferentes, de datas diferentes, mas recíprocos ou correspectivos. Tudo está na maneira de testar, no intuito das declarações.

"Êrro é interpretar-se a proibição como só vedativa de testamentos materialmente de mão comum, - testamentos em que A. e B., no mesmo papel e ao mesmo tempo, testam" $\left({ }^{20}\right)$.

$\mathrm{O}$ eminente jurisconsulto contenta-se, em tema de tal magnitude e colocando-se em flagrante dissídio com a unanimidade dos intérpretes, tanto nacionais, como estrangeiros, e ao arrepio das regras de hermenêutica, com afirmar dogmàticamente, o que, aliás, é tão de seu feitio ${ }^{(21)}$, e, mais adiante, quando formula as hipóteses que, a seu entender, o Código não proíbe, enumera, como primeira,

(19) CARLOS MAXIMILIANO, Sucessões, vol, I, n. 366, pg. 367 da $1 . .^{2}$ ed. fício de terceiro; pois o o testamento o de mañalida, é o tolher a possibilidade da revogaçacáa unilateral, característica essencial do ato de última vontade; demais, falta, a êste, outro requisito - ser livre, isento de influência ou pressão alheia" (CARLOS MAXIMILIANO, Direito

(20) PONTES DE MIRANDA, Tratado dos Testamentos, vol. I, n.o 130, pg. 303.
(21) Distinguindo onde a lei não distingue, PONTES DE MIRANDA chega, v. g., (21) Distinguindo onde a lei não distingue, PONTES DE MIRANDA chega, v. g.,
nos dar êste comentário ao art. 203 da Constituição Federal vigente, que isenta de qualquer impôsto direto os direitos autorais, bem como a remuneração dos professôres pagam o impôsto de renda global, não pagam o cedular. Porque não pagam o cedular não podem alegar as diminuiçóes que entendem com a cédula" (PONTES DE MIRANDA, o impôsto de renda é direto - năo o nega o eminente jurisconsulto. Como justifi-
cará a distinçãa que a Constituição não fềz ? Ubi lex non distinguit nec nos distinguere debemus. 


$$
-66-
$$

o fato de, "sem combinação dos cônjuges, ainda em atos da mesma data", instituírem beneficiários as mesmas pessoas $\left({ }^{22}\right)$.

O que é humano, o que é normal, o que mais se coaduna com a harmonia doméstica, com a instituição familiar, isto é, que os cônjuges combinem suas disposições de última vontade, evitando incongruências geradoras de inconvenientes sérios - e, assim procedendo, não tolhem de forma alguma a liberdade um do outro, não prejudiquem a espontaneidade de suas liberalidades, não sofram suas vontades - para PONTES DE MIRANDA é eiva irreparável para a qual a sanção única é a nulidade dos testamentos que êle considera intencionalmente conjuntivos.

O absurdo é tão palpável que dispensaria longas digressões.

$E$ ' de acentuar que não são só os autores nacionais que interpretam em dissonância de PONTES DE MIRANDA, mas também os estrangeiros que estudaram o assunto à luz das legislações de seus países, similares da nossa.

São êles unânimes na exigência da unidade do ato para que incidam as disposições de última vontade na balda de testamento conjuntivo, proibido sob pena de nulidade insanável.

O Código Civil Francês, no seu art. 968, dispõe:

"Un testament ne pourra être fait dans le même acte par deux ou plusieurs personnes, soit au profit d'un tiers, soit à titre de disposition réciproque et mutuelle $\left({ }^{23}\right)$.

PLANIOL interpreta tal preceito como exigindo ato distinto para cada testamento, de tal forma que duas pessoas estão impossibilitadas de o fazerem ao mesmo tempo e pelo mesmo ato, quer em proveito recíproco, quer de terceiro, sendo, pois, nulos os testamentos recíprocos ou conjuntos contidos no mesmo ato $\left({ }^{24}\right)$.

Portanto, para o grande mestre francês, é a unidade do ato que torna nulo o testamento conjuntivo.

Não menos clara é a lição de RENÉ SAVATIER, professor da Faculdade de Direito de Poitiers, que assevera constituir o art. 968 (22) PONTES DE MIRANDA, Tratado dos Testamentos, vol. I, n.o 131, pg. 305
(23) Semelhante é o teor do art. 781 do Código Civil Uruguaio:

(a) reciprocamente en provecho suyo o de un tercero"
$(24)$ "Chaque testament doit être contenu dans un acte distinct. Deux personne ne peuvent pas faire leur testament en même temps et par le même acte, soit qu', eile ' conjoints) sont nuls (art. 968)" (PLANIOL, Traité élémentaire de Droit Oivil, vol. III,
n. 2682, pg. 659). do Cód. Civ. Francês norma excepcional, a ser interpretada de modo restrito, não anulando, na ausência de prova de pacto sucessório, os testamentos feitos dum e doutro lado da mesma fôlha, nem os lavrados em atos separados, mas "em contemplação um do outro", com disposições correlativas, nem tampouco os idênticos de duas pessoas que nêles disponham do mesmo modo dos bens de cada uma $\left({ }^{25}\right)$.

O Código Civil Português diz no art. 1753:

"Não podem testar no mesmo ato duas ou mais pessoas, quer em proveito próprio, quer em proveito comum, quer em proveito de terceiro".

CUNHA GONÇALVES, o mais autorizado de seus intérpretes, ensina:

"A proibição do art. 1753 , porém, só respeita ao testamento de duas pessoas no mesmo documento. Nada impede, porém, que duas pessoas, p. ex., marido e mulher, façam testamento em separado, mas no mesmo dia, em ato contínuo, quer em proveito comum, quer em proveito de terceiro. Haverá, então, dois testamentos, se bem que produzindo os efeitos práticos do testamento simultâneo ou conjunto, sem os inconvenientes dêste. Estes testamentos serão absolutamente válidos, porque são atos unipessoais; cada testador pode livremente modificar ou revogar o seu testamento, assim como se presume que livremente ditaram ou escreveram a sua vontade, ainda que na realidade assim não fôsse" $\left({ }^{26}\right)$.

O Código Civil italiano de 1865 , no art. 761 , assim rezava:

"Non si può fare un testamento da due o più persone nel medesimo atto, nè a vantaggio di un terzo, ne per disposizione reciproca".

(25) "Cependant, l' artcle 968 rest une disposition exceptionnelle, a interpréter "1.0 Les testaments faits, 1 ' un au verso, l' autre au recto d' une même feuille; " autre", c'est-à-dire, contenant des dispositions correlatives; $3 .{ }^{\circ}$ 'Les testaments identiques de deux personnes, y disposant chacune, et de la même
manière, des biens de l' une et de l' autre (Civ. 25 férr. 1925, D. 1925-1.185, note manière, ,es (SAVATIER, Cours de Droit Civil, vol. III, no 1011, pg. 525 ). vivil Português, vol. IX, n. 
Quase idêntica é a redação do art. 589 do atual Código Civil Italiano, de 1942 .

"Non si può fare testamento da due o più persone nel medesimo atto, nè a vantaggio di un terzo, nè con disposizione reciproca".

ROBERTO DE RUGGIERO, professor da Universidade de Roma, na vigência do Código de 1865, escreveu:

“... por outro lado não é consentido a duas pessoas (nem mesmo sendo cônjuges) que disponham recìprocamente uma a favor da outra (testamento reciproco) ou que façam testamento juntamente no mesmo ato ainda que a favor de um terceiro ou de duas pessoas diversas (testamento conjunto)" $\left({ }^{27}\right)$.

Na vigência do atual Código de 1942, não menos categórica é a lição de LODOVICO BARASSI, professor emérito de Direito Civil na Universidade Católica de Milão, quando afirma haver testamento conjuntivo, para os efeitos do art. 589 do Código Civil Italiano, não só quando se tratar dum só ato, dum único testamento, como também quando as declarações de ambos constarem, embora separadamente, duma mesma fôlha, desde que interdependentes $\left({ }^{28}\right)$, mas que se deve distinguir o testamento correspectivo (que pressupõe a vantagem recíproca dos dois testadores) de dois testamentos separados, com disposições a favor do mesmo terceiro (herdeiro ou legatário), testamentos êsses, apesar de verbas idênticas, nìtidamente autônomos e, como tais, indubitàvelmente válidos, mesmo quando resultantes da préviia combinação de ambos os disponentes $\left({ }^{29}\right)$.

De modo semelhante ao dos Códigos apontados é o que dispõe o art. 3618 do Código Civil Argentino: (27) ROBERTO DE RUGGIERO, Instituiçóes de Direito Civit, vol. III, $\$ 145$,
pg. 551 da trad. port.

(28) "Unicità dell' atto. - Vero "testamento congiuntivo", anche agli effetti atto" considerato come negozio giuridico. Cioè due persone sono espresse in un "unico mente le dichiarazioni dei due testatori sono espresse separatamente (però sempre nel medesista che nel loro contenuto essi siano interdipendenti" "BARASSI, (29) "Dobbiamo distinorte, n. 106 , pg. 300).

che presuppone la reciprocità, cioè il reciproco vantaggio dei due testatori - da due testament in cui si ritrovi la disposizione di ultima volonta "a favore della medesima terza persona" ubbio; anche se vi è stata di fatto (giuridicamente sarebbe irrilevante) un intesa tra (B) morte, n.o 107, pg. 304)
"Un testamento no puede ser hecho en el mismo acto por dos o más personas, sea en favor de un tercero, sea a título de disposición recíproca e mútua".

Comentando-o, diz o Professor JOSÉ ARIAS, catedrático nas Universidades de Buenos Aires e La Plata:

$$
\begin{aligned}
& \text { "Observese el límite de la prohibición: en el mismo } \\
& \text { acto" }\left({ }^{30}\right) \text {. }
\end{aligned}
$$

O eminente Professor HECTOR LAFAILLE, catedrático jubilado da Universidade de Buenos Aires e autor de um magnífico tratado de Direito Civil, entende não haver nenhum impedimento a que duas pessoas, de comum acôrdo, façam dois testamentos separados, que cada uma poderia revogar quando bem entendesse $\left({ }^{31}\right.$ ).

Opinando sôbre um caso de testamento conjuntivo, FRANCISCO MORATO, professor emérito da Universidade de S. Paulo, emitiu brilhante parecer, em que, entre outras considerações, disse:

"Não colhe obtemperar que a revogação do testamento recíproco importa decepção ou deslealdade ao defunto, o qual não testaria na forma em que o fêz, se previsse que o cônjuge supérstite derrogaria ou revogaria o testamento comum. Conforme escreve VALASCO, "nec obstat quod ex hujusmodi revocatione resultat deceptio. defunctis, quem non credimus institutum superstitem conjugem, si putaret eum revocaturum institutionem factam; imputet enim sibi, qui naturam ultimarum voluntatem revocabilem esse, scire debuerat" (Consult. VII - n. 7)" (32).

Seria o caso de invocar a favor da liberdade da vontade de cada testador os velhos brocardos do Direito Romano, fazendo prevalecer apenas a vontade que fôr de conformidade com a permissão legal e nunca o que fôr oposto à lei:

(30) JOSÉ ARIAS, Sucesiones, pg. 97.

Dersonas puedan de común acuerdo hacer dos testamentos separados, pero cada uno de elos estaría habilitado para dejar sin
efecto el suyo, cuando le pareciera oportuno" (LAFAILLE, Curso de Derecho Civil efecto el suyo, cuando le pareciera oportuno" (LAFAILLE, Curso de Derecho Civil -
Sucesiones, tomo II, no 256 , pg. 192). (32) FRANCISCO MORATO, Miscelânea Jurídica, vol. II, pgs. 548-549. Consultado, em 1906, sôbre testamento de mão comum, conclusão é a a seguinte:
"Portanto, Du Umbelina pode fazer outro testamento e instituir seu herdeiro outra qualquer pessoa. Não pode haver dúvida a respeito, porque o testamento de que se trata, de um dos testadores são expressa ou presumidamente em retribuicão das disposicóos do
outro (Veja-se C. da Rocha, § 727 e. nota ao $\$ 728$ )" (LAFAYETTE, Pareceres, vol. I, outro (Vejest
pg. 430$)$. 
"In omnibus etenim testatoris voluntatem, quae legitima est, dominari censemus" ( $\left.{ }^{33}\right)$.

"Semper hanc unam habemus intentionem dispositiones morientium esse firmas, nisi resultent legi et aperte contrariae sint his quae illi placent" $\left({ }^{34}\right)$

Julgando, em 1928, um caso de testamento de mão comum feito na vigência do direito precodificado, o então Tribunal de Relação, hoje Tribunal de Justiça, do Estado do Rio de Janeiro, assim se manifestou a respeito de tal forma de testamento:

"Ora, o testamento conjuntivo nada mais é do que uma forma externa de disposição causa mortis, facultada na anterior legislação e que a nova aboliu, sem entretanto obstar que os cônjuges em instrumentos separados, ou por qualquer dos outros meios comuns de testamento, possam exprimir a mesma vontade que lhe era dado denunciar por aquêle meio. Nenhuma alteração, pois, ocorreu na substância do direito quanto à disposição, e $\operatorname{sim}$ apenas a eliminação de um modus faciendi, o repúdio de uma forma que o legislador reconheceu ser defeituosa, ou apresentar inconvenientes. Aliás, o próprio capítulo do Código Civil em que se acha compreendido o art. 1630 , tendo por epígrafe a frase - das formas ordinárias do testamento - , bem indica o aspecto externo do caso, a sua feição formulária” ( $\left.{ }^{35}\right)$.

De todo o exposto, estas são, sem possibilidade de dúvida, as

\section{O N C L U S Õ E S :}

1 - O testamento conjuntivo, proibido pelo art. 1630 do Código Civil, Brasileiro, é tão-sòmente o constante dum ato único.

2 - São válidos os testamentos separados, de várias pessoas, mesmo feitos no mesmo dia, dispondo reciprocamente ou a favor de terceiros.

3 - Nada impede que diversas pessoas disponham de seus bens de acôrdo entre si, desde que o façam guardando sua liberdade, em atos separados.

Pôrto Alegre, 13 de junho de 1950.

(33) L. $23, \& 2$ a, C., de legatis, 6,37

(35) Revista de Critica Judiciaria, vol. XI, pgs. $338-339$

\section{RELATÓRIO E PARECER}

\section{Relator: LEÔNIDAS PAIM CAMINHA}

1 - Propõe-se o autor do trabalho que ora relatamos a demonstrar, com apoio em doutrina fartamente citada, que a proibição do artigo 1.630 do Código Civil refere-se, ùnicamente, ao testamento conjuntivo, isto é, ao testamento feito por duas ou mais pessoas em um único ato.

Inicia a sua exposição dizendo que o testamento conjuntivo penetrou no direito pátrio autorizado pelos praxistas, sendo, mais tarde, consagrado por Teixeira de Freitas, em nota à $3 .^{\mathrm{a}}$ edição da "Consolidação das Leis Civis" e por Carlos de Carvalho, em sua "Nova Consolidação das Leis Civis". Ficou, assim, espécie aceita pelo nosso direito anterior ao Código Civil. Proibindo-o expressamente, bem andou o Código Civil, pois esta forma não se ajustava aos requisitos primordiais do testamento: ato personalíssimo, unilateral, gratuito, solene e revogável.

Em seguida, refere a legislação de outros países onde o testamento conjuntivo é aceito, tais como a inglêsa, a alemã, a austríaca e a venezuelana.

Após conceituar as três formas de testamento conjuntivo proibidas pelo artigo 1.630 citado, passa o autor a interpretar o texto legal referido, dizendo que "sempre se entendeu da essência do testamento conjuntivo sua feitura no mesmo ato. Portanto, continua o autor, a proibição do artigo 1.630 do Código Civil só se pode referir a testamento em que os cônjuges, no mesmo ato, disponham de suas vontades".

Em abôno dessa exegese do texto legal, nvoca o autor os ensinamentos de grandes autoridades na matéria, citando trechos das obras de Ferreira Alves, Cândido de Oliveira Filho, Carvalho Santos, Itabaiana e Carlos Maximiliano.

Como opinião divergente dêsse modo de interpretar a proibição legal, aponta o autor a de Pontes de Miranda, exposta em sua notável obra "Tratado dos Testamentos". Para Pontes de Miranda, "onde há reciprocidade e correspectividade, há intenção de testar em conjunto. Não é preciso que se dê simultâneamente a identidade ou continuidade espacial. Dois testamentos podem ser em atos diferentes, de datas diferentes, mas recíprocos ou correspetivos. Tudo está na maneira de testar, no intuito das declarações".

"Erro é interpretar-se a proibição como só vedativa de testamentos materialmente de mão comum, - testamentos em que $\mathrm{A}$ e B, no mesmo papel e ao mesmo tempo, testam". 
Rebatendo a interpretação de Pontes de Miranda ao artigo 1.630 citado, o autor adverte que não há restrição à liberdade dos cônjuges quando êstes, para "evitar incongruências geradoras de inconvenientes sérios", combinam suas disposições de última vontade, fato êste que não prejudica a espontaneidade de suas liberalidades.

Estas afirmações do autor estão concordes com as de Planiol, Savatier, Cunha Gonçalves, Barassi e Lafaille, que a seguir transcreve.

Finalmente, em defesa de seu ponto de vista, transcreve uma decisão do Tribunal de Justiça do Rio de Janeiro, então Tribunal de Relação, segundo a qual, a proibição do artigo 1.630 tem enderêço exclusivo à forma de testar, por que "o próprio capítulo do Código Civil em que se acha compreendido o artigo 1.630, tendo por epígrafe a frase - das formas ordinárias do testamento - , bem indica o aspecto externo do caso, a sua feição formulária".

Finaliza o autor admitindo as seguintes conclusões:

a) $\mathrm{O}$ testamento conjuntivo. proibido pelo artigo 1.630 do Código Civil Brasileiro, é tão-sòmente o constante dum ato único.

b) São válidos os testamentos separados, de várias pessoas, mesmo feitos no mesmo dia, dispondo recìprocamente ou a favor de terceiros.

c) Nada impede que diversas pessoas disponham de seus bens, de acôrdo entre si, desde que o façam guardando sua liberdade, em atos separados.

2 - O eminente autor da tese ora relatada, professor catedrático de Direito Civil das Universidades do Rio Grande do Sul e Católico, sustenta brilhantemente opinião a respeito da intepretação do artigo 1.630 do Código Civil, da qual não se pode divergir: a proibição legal refere-se sòmente ao testamento feito por duas ou mais pessoas em um único ato, sendo a unicidade do ato característica exclusiva do testamento conjuntivo.

Razão nenhuma se encontra nas afirmações de Pontes de Miranda, segundo o qual basta haver simultaneidade, correspectividade ou reciprocidade para se achar o testamento fulminado pela sanção legal em referência, por que a proibição é endereçada ùnicamente ao testamento conjuntivo, quer seja êle simultâneo, recíproco ou correspectivo. Para, pois, bem apreender-se a proibição legal tornase necessário ter a noção de testamento conjuntivo. Por testamento conjuntivo se entende o que é feito, por duas ou mais pessoás, em um único ato. Esta noção de testamento conjuntivo encontra-se perfeitamente enquadrada nas origens que teve nas Ordenações Filipinas, segundo a qual marido e mulher sejam considerados como um corpo ou como uma pessoa. Restringe-se, ùnicamente, ao aspecto formal do testamento.

Com muita exatidão, pois, afirma o autor que, na ausência de prova de pacto sucessório, não se deve anular os testamentos feitos em atos separados, por duas pessoas, em contemplação uma da outra, ou de terceiros.

Por estas considerações, submetendo o presente trabalho à apreciação da douta Comissão, opinamos pela sua aprovação.

\section{DEBATES EM PLENÁRIO:}

O SR. PRESIDENTE - José Salgado Martins -

Vamos passar à discussão da tese "Unidade de Ato no Testamento Conjuntivo", de autoria do professor Armando Dias de Azevedo. E' relator o dr. Leônidas Paim Caminha, a quem concedo a palavra.

O SR. LEÔNIDAS PAIM CAMINHA - Relatório da tese "Unidade no Testamento Conjuntivo", de autoria do professor Armando Dias de Azevedo.

\section{(LÊ O RELATÓRIO E PARECER)}

Estas conclusões foram aprovadas por unanimidade pela Comissão de Direito Civil, no seio da qual foi vitoriosa a sugestão de que a tese deve ser aprovada com destaque pelo plenário.

O SR. PRESIDENTE - Está em discussão a tese em aprêço.

Se ninguém quiser fazer uso da palavra, vou submetê-la a votos, antes, porém, relendo as suas conclusões, que são as seguintes:

"1 - O testamento conjuntivo, proibido pelo art. 1630 do Código Civil, Brasileiro, é tão-sòmente o constante dum ato único.

2 - São válidos os testamentos separados, de várias pessoas, mesmo feitos no mesmo dia, dispondo reciprocamente ou a favor de terceiros.

3 - Nada impede que diversas pessoas disponham de seus bens, de acôrdo entre si, desde que o façam guardando sua liberdade, em atos separados".

Em votação. Os senhores Congressistas que aprovam as conclusões que acabam de ser lidas, queiram ficar sentados. (Pausa). Aprovadas. (Palmas). 